\title{
La cuestión agraria cubana aciertos y desaciertos en el período de 1975-2013: la necesidad
}

\section{de una tercera reforma agraria.}

\author{
Tatiana Wonsik Recompensa Joseph \\ Universidade Federal de Santa Maria, Santa María, Brasil \\ Email: twonsik@gmail.com \\ Lázaro Camilo Recompensa Joseph \\ Universidade Federal de Santa María, Santa María, Brasil \\ Email: camilojoseph@hotmail.com
}

\begin{abstract}
Resumen: El presente trabajo estudia las principales transformaciones introducidas en la economía cubana en el periodo de 1975 a 2013, con un énfasis particular en la Tercera Reforma Agraria puesta en vigor a partir de 1993, la cual significó el tránsito hacia un nuevo modelo agrario cuyo objetivo principal sería resolver el problema de la soberanía alimenticia. Con esta nueva reforma agraria se reconfigura una vez más la forma de tenencia de la tierra en Cuba, estando actualmente el 54\% (de las tierras) en manos del Estado y el 46\% restante es propiedad no estatal. De esta forma, el objetivo principal de este trabajo es analizar, describir y explicar la necesidad de realizar la tercera reforma agraria a partir de la problemática relacionada con la cuestión agraria cubana, sus principales aciertos y desaciertos en el periodo analizado. Para facilitar el análisis, estableceremos una periodización del proceso histórico que utilizaremos como guía en nuestra exposición. El primer periodo comprende de 1975 al 1990, periodo en el cual se institucionaliza el país, se impulsan las CPA y se prioriza el desarrollo de la industria azucarera. El segundo periodo va del año 1991 hasta la actualidad, en el cual se toman un conjunto de medidas para contrarrestar los efectos negativos en la economía y la sociedad cubana producto de la desaparición del campo socialista; destacándose la Tercera Reforma Agraria de 1993 como la principal medida tomada por la Revolución.
\end{abstract} rrollo rural.

Palabras clave: Reforma Agraria, cuestión agraria, economía agrícola, desa-

\section{The cuban agrarian matter, successes and failures in the period 1975-2013: the need for a third agrarian reform.}

\footnotetext{
Abstract: The present paper studies the main transformations introduced in the Cuban economy in the period from 1975 to 2013, with emphasis on the Third Agrarian Reform implemented since 1993, which meant the transition to a new agrarian model, whose main objective would be to solve the problem of food sovereignty. This new agrarian reform reconfigures once more the form of land
} 
tenure in Cuba, with 54\% of the land currently owned by the state and the remaining $46 \%$ being non-state owned. Thus, the main objective of this work is to analyze, describe and explain the need to carry out the third agrarian reform, based on the problems related to the Cuban agrarian question, its main successes and failures in the period analyzed. To facilitate the analysis we will establish a periodization of the historical process that we will use as a guide in our exhibition. The first period covers from 1975 to 1990, period in which the country is institutionalized, CPAs (Agricultural Production Cooperatives) are raised and the development of the sugar industry is prioritized. The second period goes from 1991 to present days, in which a set of measures are taken to counteract the negative effects on the Cuban economy and society resulting from the disappearance of the socialist block. Standing out the Third Agrarian Reform of 1993, as the main measure taken by the Revolution.

Keywords: Agrarian reform, agrarian matter, agricultural economy, rural development.

\section{Questão agrária cubana, sucessos e fracassos no período 1975-2013: a necessidade de uma terceira reforma agrária.}

Resumo: Este artigo examina as principais alterações introduzidas na economia cubana no período de 1975 a 2013, com ênfase especial sobre a Terceira Reforma Agrária pôs em vigor desde 1993, o que significou a transição para um novo modelo agrícola que principal objetivo resolveria o problema da soberania alimentar. Com esta nova reforma agrária reconfigura uma vez mais a forma de posse da terra em Cuba, sendo atualmente 54\% (terra) de propriedade do Estado e os restantes $46 \%$ é estatal. Assim, o principal objetivo deste artigo é analisar, descrever e explicar a necessidade para a terceira reforma agrária dos problemas relacionados com a questão agrária cubana, seus principais pontos fortes e fracos no período de referência. Para facilitar a análise, vamos estabelecer uma periodização do processo histórico que usamos para guiar a nossa discussão. O primeiro período compreende 1975-1990, um período em que o país é institucionalizado, as APCs são accionados e desenvolvimento da indústria de açúcar é dada prioridade. O segundo período é de 1991 até o presente, em que um conjunto de medidas são tomadas para neutralizar os efeitos negativos sobre a economia e produto sociedade cubana do desaparecimento do campo socialista; Terceiro destacando a Reforma Agrária de 1993 como a principal medida tomada pela Revolução.

Palavras chave: reforma agrária, questão agrária, economia agrícola, de desenvolvimento rural.

$* * *$

\section{Introducción}

Como parte del proceso de institucionalización de la revolución cubana apartir del Primer Congreso del Partido Comunista de Cuba en 1975 (y similar a lo ocurrido en otros países que intentaron construir el socialismo bajo la influencia del "modelo soviético"), el Estado cubano promovió lanecesidad de organizar,en formas superiores, la producción individual campesina incentivando el cooperativismo en el sector 
agropecuario. Fueron creadasasílas primeras Cooperativas de Producción Agropecuaria (CPA), estimulando el desarrollo delas (ya existentes) Cooperativas de Crédito y Servicio (CSS). De esta forma, al final de los años sesenta, y principios delos ochenta,se conforman en el país la gran mayoría de las CPA. Estas son cooperativas de trabajo asociado creadas fundamentalmente por campesinos beneficiados con la 1ra y 2da reforma agraria, realizadas en 1959 y 1963 respectivamente, los cuales vendieron sus tierras a las cooperativas para constituirlas como propiedad colectiva.

Este proceso (de cooperativismo agrícola), se desarrollóde forma estable hasta finales de los años 90. Durante ese periodo convivió el cooperativismo agrícolajuntocon la granempresaestatal, caracterizada por el alto grado de centralización de su gestión. Así, en el año 1990, la estructura de tenencia de la tierra de Cuba era la siguiente: en manos del sector privado se concentraba el $14 \%$ de las tierras, el sector cooperativo absorbía el 11\% y el Estado el 75\% de todas las tierras del país.

Con la desaparición del campo socialista en 1991 y la agudización del bloqueo económico de los EUA, el estado cubano se vio obligado a introducir un conjunto de modificaciones estructurales en el modelo económico del país y en el agropecuario en particular.

Entre las principales transformaciones introducidas en este periodo, se destaca la Tercera Reforma Agraria puesta en vigor a partir de 1993, la cual significó el tránsito hacia un nuevo modelo agrario, cuyo objetivo principal sería resolver el problema de la soberanía alimenticia $^{1}$. Con esta nueva reforma agraria se reconfigura una vez más la forma de tenencia de la tierra en Cuba, donde actualmente el 54\% (de las tierras) se encuentra en manos del Estado y el $46 \%$ restante es propiedad no estatal.

En este marco, el objetivo principal de este trabajo es analizar, describir y explicar la necesidad de realizar la tercera reforma agraria a partir de la problemática relacionada con la cuestión agraria cubana, sus principales aciertos y desaciertos en el periodo de 1975-2013.

Para facilitar el análisis estableceremos una periodización del proceso histórico que utilizaremos como guía en nuestra exposición. El primer periodo comprende de 1975 al 1990, periodo en el cual se institucionaliza el país, se crean las CPA y se prioriza el desarrollo de la industria azucarera. El segundo periodo va del año 1991 hasta la actualidad, en el cual se toman un conjunto de medidas para contrarrestar los efectos negativos en la economía y la sociedad cubana producto de la desaparición del campo socialista. Aquí destaca la Tercera Reforma Agraria de 1993como la principal medida tomada por la Revolución. 


\section{Cuestión Agraria en Cuba: Creando las condiciones del desarrollo agrícolaapartir de 1975}

La primera gran transformación del fondo de tierras agrícolas en Cuba tuvo lugar el 17 de mayo de 1959 con la promulgación de la 1ra Ley de Reforma Agraria. Con la aprobación y ejecución de esta ley quedo proscrito el latifundio en Cuba,colocando como pose o tenencia máxima de propiedad de tierras para una persona natural o jurídica, 30 caballerías (cab) ó 402,60 hectáreas (ha) de tierras. Esta 1ra Ley de Reforma Agraria tambiénpermitió: a) una rápida disminución del desempleo,b) la erradicación del hambre y la explotación a la que estaban sometidos los trabajadores agrícolas, y c) estatizar alrededor del $40 \%$ de la propiedad rural, haciendo propietarios a casi 100000 campesinos.

Posteriormente, el 3 de octubre de 1963, se promulga una 2da (y definitiva) Ley de Reforma Agraria, la que establece como límite máximo de pose o tenencia de tierra para una persona natural o jurídica 5 caballerías ó 67,10 hectáreas de tierras. Con esta medida, se liquida de una vez la gran propiedad latifundista sobre la tierra y los burgueses agrarios,pasando a manos del Estado cubano aproximadamente el 70\% de las tierras agrícolas del país, elementoque permitió iniciar el proceso de reestructuración de la producción agropecuaria.

Debemos destacar quela aprobación de esas sendas leyes de Reforma Agraria se convirtió en el determinante que enfrentó directamente al imperialismo norteamericano contra Cuba. En este periodo, los EUA, a modo de represalia realizaron y ejecutaron variosplanes de agresiones sociales y económicas contra Cuba,como fueron: la eliminación de la cuota preferencial del azúcar, la negativa de refinar petróleo ruso en las refinerías de petróleo propiedad de los EUA ubicadas en suelo cubano y el establecimiento en 1962 del bloqueo económico a Cuba que perdura hasta el día de hoy.

Asimismo, en este periodo, a la parde la $1^{\mathrm{a}} \mathrm{y} 2^{\mathrm{a}}$ Reforma Agraria, el campesinado cubano no advirtió la necesidad de organizarse en formas superiores de producción, debido entre otros elementos: a) al respaldo legal recibido por parte del gobierno con la aprobación de estas Leyes de Reforma Agraria; b) la aplicación en sus tierras de las técnicas existentes en el país; c) la disponibilidad de créditos, insumos y fuerza de trabajo; d) la garantía del acopio de sus productos a precios favorables y e) la falta de tradición y experiencia cooperativa en el campesinado, entre otros.

Atento a esta situación, ellíder de la revolución cubana, Fidel Castro Ruz, en $1974^{2}$, llamóa pensar en nuevas formas de trabajo y de cooperación en la agricultura y expresó:

(...) ya es conveniente, al cabo de 15 años de reforma agraria, que nuestros campesinos vayan pensando en formas superiores de cooperación, en formas superiores de trabajo (...). Desde luego, en un 
camino progresivo, despacio y en base al principio que hemos establecido que es clave: la voluntariedad. ¡Este principio no podrá ser abandonado jamás!

(...) es necesario que nuestro campesinado vaya pensando en formas superiores de producción, puesto que el curso del desarrollo del país no se puede detener, puesto que las necesidades crecientes de la población hacen necesaria una incesante tecnificación de nuestra agricultura, y un aprovechamiento óptimo y total de la tierra. (...) Ver,Castro, (1974).

Con la realización del I Congreso del Partido Comunista de Cuba en diciembre de 1975, quedaron aprobadas diferentes tesis y resolucionesclaves para el desarrollo del país. Para interés de este trabajo, destacaremos y analizaremos brevemente las siguientes tesis y resoluciones: a) la implantación en 1976del nuevo Sistema de Dirección y Planificación de la Economía (SDPE) basado en la experiencia de los países socialistas europeos. El SDPE fue concebido como el conjunto de elementos y procedimientos que regulaban la organización, la gestión y control de las actividades económicas basada en la planificación centralizada. La principal premisa de sustentación es la propiedad estatal de los principales medios de producción. El SDPE también reconocía la existencia de las relaciones monetarias mercantiles en todas las actividades productivas y tentaba promover el autofinanciamiento y la descentralización en la gestión empresarial estatal.b) la aprobación de la Tesis "Sobre la cuestión agraria y las relaciones con el campesinado",en laque se analizan las profundas transformaciones operadas en nuestros campos y donde seestablece entre otros aspectos, el paso gradual hacia formas superiores de producciónen la agricultura cubana, siempre basado en el respeto estricto a la voluntad delcampesinado.En dichas Tesis se destaca:

(...) Pasar hacia formas superiores de producción no es solouna necesidad económica para lograr el aprovechamiento óptimo de la tierra (y losrecursos humanos), sino también una necesidad social, para lograr el avance de la familia campesina, su elevación a formas socialistas de convivencia $(\ldots)^{3}$. (Tesis y Resoluciones del I Congreso del PCC, 1975, pág. 31).

Debemos destacar que los caminos posibles hacia formas superiores de producción fueron definidos por Fidel en 1974, en la Plata cuando expresó:

(...) aquí hay dos caminos que podemos seguir: hay el camino de la integración a planes y hay el camino de la cooperación”. ¿Cuál de los caminos debemos seguir? La respuesta adecuada dependerá del examen concreto de cada zona del país, del programa de desarrollo de la economía nacional y de la voluntad del propio campesino (...). (Ibíd.). 
Así, el año de 1976 marca el inicio de una segunda etapa en el proceso de industrialización y desarrollo de la economía cubana, en ese sentido la industria pasa a ser el sector estratégico, o sea, en esta nueva etapa el sector agrícola cede su papel protagónico central al sector industrial. (Ver Tabla N 1.). Durante el periodo de 1975-1985 el valor agregado bruto de la industria manufacturera creció con mayor celeridad (7\%) que el Producto Interno Bruto (6\%) aumentando su participación en 2,7\% (26,9\% $\left.{ }_{1985}-24,2 \%{ }_{1975}=2,7 \%\right)$ entre el 1975 y 1985 . Ello se explica por la prioridad concedida a este sector dentro del programa de inversiones públicasdel país en el contexto general de integración con la comunidad socialista y del fortalecimiento de los controles macroeconómicos internos. (Ver Tabla $\mathrm{N}^{\circ} 2$ )

En este periodo se estableció un nuevo marco institucional que favoreció sustancialmente el proceso de reformas económicas. El 24 de febrero de 1976 se proclamó una nueva Constitución de la República de Cuba, luego de un plebiscito nacional. Se reestructuraron los Organismos de la Administración Central del Estado, destacándose en particular la creación del Comité Estatal de Finanzas, al mismo tiempo que se reorganizó el sistema de empresas públicas y de unidades presupuestadas. Se propició una descentralización gubernamental con el establecimiento en 1976 de una nueva División Político-Administrativa del país con 14 provincias y 169 municipios.

TablaN ${ }^{\circ}$

Estructura del Producto Interno Bruto 1975-1990. (\%)

\begin{tabular}{|l|c|c|c|c|}
\hline \multicolumn{1}{|c|}{ Clase de actividad } & $\mathbf{1 9 7 5}$ & $\mathbf{1 9 8 0}$ & $\mathbf{1 9 8 5}$ & $\mathbf{1 9 9 0}$ \\
\hline \multicolumn{1}{|c|}{ Producto interno bruto } & 100,00 & 100,00 & 100,00 & 100,00 \\
\hline 1. Agricultura, caza, silvicultura y pesca & 13,52 & 12,22 & 9,30 & 9,24 \\
\hline 2. Explotación de minas y canteras & 0,60 & 0,70 & 0,53 & 0,48 \\
\hline 3. Industrias manufactureras & 24,20 & 21,15 & 26,88 & 24,41 \\
\hline 4. Electricidad, gas y agua & 1,03 & 1,75 & 1,84 & 2,39 \\
\hline 5. Construcción & 6,23 & 6,11 & 6,59 & 7,93 \\
\hline 6. Comercio, restaurantes y hoteles & 32,32 & 31,49 & 28,88 & 25,97 \\
\hline 7. Transportes, almacenamiento y & 5,30 & 6,58 & 6,54 & 6,33 \\
\hline
\end{tabular}

Fuente: CEPAL y Oficina Nacional de Estadística de Cuba. 


\section{Tabla $\mathrm{N}^{\circ} 2$}

Estructura de las inversiones según periodos y años seleccionados. (\% sobre el volumen total de la inversión bruta por sectores. A precios corrientes. Incluye todas las esferas de la economía estatal civil).

\begin{tabular}{|l|c|c|c|c|c|c|c|c|}
\hline Sector & $\mathbf{7 1 - 7 5}$ & $\mathbf{7 6 - 8 0}$ & $\mathbf{8 1 - 8 4}$ & $\mathbf{1 9 8 5}$ & $\mathbf{1 9 8 6}$ & $\mathbf{1 9 8 7}$ & $\mathbf{1 9 8 8}$ & $\mathbf{1 9 8 9}$ \\
\hline Industria & 21 & 35 & 36 & 38,4 & 34,1 & 32,1 & 32,8 & 33,3 \\
\hline Agropecuária & 29 & 19 & 24 & 21,6 & 22,5 & $22 ., 6$ & 21,7 & 22,2 \\
\hline
\end{tabular}

Fuente: Elaborado sobre la base de Comité Estatal de Estadísticas. AnuariosEstadísticos 1986, 1989.

Debemos destacar quedurante el quinquenio 1981-1985 seprofundizó en la reforma económica iniciada en 1976 con vistas a mejorar la productividad y laeficiencia de las entidades productivas. A inicios de los años ochenta se implantó el Mercado Libre Campesino con lacorrespondiente desregulación de precios, "mercado" que imperó en el país hasta su eliminación a mediados de dichodecenio. En 1981 se decretaron la reforma salarial y de precios. La primera contribuyó amejorar la correlación salario medio-productividad en tanto que la segunda influyó en elfortalecimiento de la autogestión de las empresas públicas con el correspondiente aumento en susniveles de eficiencia.Al mismo tiempo, en este período comienza a fomentarse en el país el cooperativismo campesino bajo el principio de la voluntariedad. El objetivo de tecnificar y humanizar el trabajo agrícola y de construir modernas comunidades electrificadas, atrajo a gran parte del campesinado cubano, especialmente a las mujeres. Aproximadamente un tercio de las fincas, que comprendían el 51,3\% de las tierras campesinas, se integraron a la creación de las Cooperativas de Producción Agropecuaria (CPA) entre 1977 y 1987.

Las Cooperativas de Producción Agropecuaria (CPA) instituyeron desde su surgimiento una nueva forma de producción donde los campesinos agruparon sus tierras y demás medios de producción a los fines del trabajo colectivo, eliminando la propiedad privada y restableciendo una nueva forma de propiedad basada en la cooperación y ayuda de todos sus miembros para la obtención de un beneficio común. El principio esencial de integración a dicha cooperativa lo constituye la voluntariedad y había sido esbozado por Lenin en el denominado "Plan Leninista de Cooperación". (Ver Balado Pampin, 2010).La CPA es la asociación voluntaria de agricultores pequeños sobre la base de la unificación de sus tierras y demás medios de producción, cuya gestión goza de autonomía con respecto al Estado, aunque éste le brinda toda la ayuda necesaria. Sus características son:

- Unión voluntaria de los campesinos.

- Cultivan en común la tierra.

- Se rigen por los estatutos.

- Poseen personalidad jurídica propia.

- Trabajan por un plan aprobado por su Asamblea General. 
Polis, Revista Latinoamericana, No 47, 2017

La CPA tiene los fines fundamentales siguientes:

- Desarrollan la producción agropecuaria.

- Elevan la productividad del trabajo y la aplicación de la ciencia y la técnica.

- Satisfacen las necesidades materiales y culturales de los cooperativistas y sus familias.

- Desarrollan la participación consciente de los cooperativistas y sus familiares en las actividades económicas, políticas y sociales del país.

Pueden incorporarse a la Cooperativa las personas mayores de 16 años que sean: agricultores pequeños (propietarios o en usufructo); trabajadores agrícolas y familiares de agricultores que laboren las tierras, siendo aprobado su ingreso por la Asamblea de Cooperativistas. La tierra y demás medios de producción aportados a la Cooperativa son tasados y amortizados para lo cual la Cooperativa destinará parte de sus ingresos. La Cooperativa se dirige conforme al principio del centralismo democrático, por su Asamblea General y su Junta Directiva, la que es elegida por sus asociados. El patrimonio de la Cooperativa lo integran: la tierra; medios e instrumentos de producción; instalaciones; plantaciones; animales; y recursos financieros.Toda Cooperativa al concluir el ciclo económico determinará el ingreso total, procederá al pago de impuestos y otras obligaciones por préstamos recibidos y el saldo restante lo distribuirá de la forma siguiente:

- Pago de bienes aportados (25 - $30 \%)$.

- Inversiones y desarrollo (15 \% o más).

- Actividades sociales, culturales y recreativas (5\%).

- Medios de rotación (15\%).

- Distribución de utilidades entre los cooperativistas (50\%).

En este periodo, junto con las CPA, coexistían la Cooperativas de Crédito y Servicios (CCS) (creadas con las 1ra y 2da ley de Reforma Agraria) las cuales constituyen una forma simple de cooperación en la que el campesino conserva la propiedad individual de su tierra y demás medios de producción y mediante esta organización se tramitan y viabiliza la asistencia técnica y financiera que el Estado le brinda:

Los fines de las CCS son los siguientes:

- Planificar, controlar, recibir y utilizar en forma organizada los recursos materiales y financieros, así como la asistencia técnica que el Estado le proporciona.

- Fomentar la ayuda mutua y otras formas de cooperación entre los agricultores y sus familiares.

- Contribuir al mejoramiento de la situación económica y social de sus integrantes.

Además, las CCS, constituyen una entidad económico-social, tienen personalidad jurídica propia, se rigen por su reglamento y su Junta Directi- 
va es elegida por la Asamblea General. Las CCS pueden adquirir para uso colectivo de sus miembros, equipos, turbinas, maquinarias e instalaciones. Pueden ser socios de las CCS, los agricultores pequeños mayores de 16 años y demás familiares vinculados a la producción de las fincas. La creación de las CPA, junto con las CCS dieron lugar a un importante movimiento cooperativista en la agricultura cubana. Según Figueroa y Averoff (2001), la evolución del cooperativismo en Cuba puede enmarcarse en tres etapas:

La $1^{\text {a }}$ etapa de 1977 a 1983: caracterizada por la multiplicación acelerada del número de cooperativas y de campesinos asociados durante una época de crecimiento económico nacional, y predominio de las pequeñas cooperativas de gestión muy eficiente. Desde 1981 la política de agrandamiento de las CPA tuvo efectos negativos, que se hicieron patentes a partir de 1983.

La 2a etapa de 1984 a 1987: se distingue por la disminución creciente de la integración a las cooperativas de nuevos campesinos; gigantismo cada vez más acentuado de estas entidades; disminución de la rentabilidad y aumento del número de cooperativas no rentables, con un período crítico entre 1986 y 1987 coincidente con la fase recesiva de la economía nacional.

La $3^{\text {a }}$ etapa de 1988-1993: se destaca en la misma, el agotamiento y parálisis del movimiento de transformación cooperativa del campesinado. En este periodo el apoyo estatal se concentró en el fortalecimiento del sector de las CPA y no en la expansión del movimiento cooperativo. Si bien la crisis económica de 1991-93 afectó a las CPA, su repercusión fue menor cuando comparada con la crisis de 1986-87. La Tabla $\mathrm{N}^{\circ} 3$, refleja la evolución de estas formas de organización de la producción campesina en el periodo de 1977-1995.

\section{Tabla No3 \\ Evolución de las CPA y CCS 1977-1995}

\begin{tabular}{|l|c|c|c|c|c|c|}
\hline \multicolumn{1}{|c|}{ Cooperativas } & $\mathbf{1 9 7 7}$ & $\mathbf{1 9 8 0}$ & $\mathbf{1 9 8 5}$ & $\mathbf{1 9 9 0}$ & $\mathbf{1 9 9 5}$ & $\begin{array}{c}\text { Rel 95/77 } \\
\text { (veces) }\end{array}$ \\
\hline Total de CPA & 137 & 1035 & 1380 & 1305 & 1156 & 8,4 \\
\hline Superficie en Mha & 25.5 & 218.0 & 1072.1 & 838.9 & 743.1 & 29,14 \\
\hline Sócios & 5030 & 30048 & 70800 & 61963 & 62257 & 12,4 \\
\hline Total de CCS & 1735 & --- & --- & --- & 2654 & 1,5 \\
\hline Superfície en Mha & 820.3 & --- & --- & --- & 905.8 & 1,10 \\
\hline Socios & 85497 & --- & --- & --- & 153641 & 1,79 \\
\hline
\end{tabular}

Fuente: Balado Pampin, 2010.

Observamos que en este periodo de reorganización socio económica productiva de la economía cubana, el desarrollo del cooperativismo agrícola se mantiene estable, conviviendo con el predominio de la empresa 
estatal de grande escala de producción y elevado grado de centralización de su gestión. O sea, la estructura de tenencia de la tierra vuelve a modificarse a partir de 1990, donde en manos del sector privado concentrase el 14\%, el sector cooperativo detiene el 11\% y el Estado el 75\% de todas las tierras del país, como se refleja en la Tabla $\mathrm{N}^{\circ} 4$.

\section{Tabla $N^{\circ} 4$}

Distribución y uso de la tierra en Cuba, según la forma de propiedad 1974-1990

\begin{tabular}{|c|c|c|c|c|}
\hline \multirow[b]{3}{*}{ Detentor } & \multicolumn{2}{|l|}{1974} & \multicolumn{2}{|c|}{1990} \\
\hline & \multicolumn{2}{|c|}{ Sup. Total $=109884004,00$} & \multicolumn{2}{|c|}{ Sup. Total $=109884004,00$} \\
\hline & $\begin{array}{c}\text { Sup. Agrícola } \\
5631000,00\end{array}$ & $(\%)$ & $\begin{array}{c}\text { Sup. Agrícola } \\
6741000,00\end{array}$ & $(\%)$ \\
\hline Estatal & 3941700,00 & 70 & 5055750,00 & 75 \\
\hline No estatal & 1689300,00 & 30 & 1685250,00 & 25 \\
\hline - $\quad$ Privado & 919751,00 & 16,33 & 943740,00 & 14 \\
\hline - Arrendatários & nde & nde & nde & nde \\
\hline - $\quad$ CPAs & 0 & 0 & 741510,00 & 11 \\
\hline - $\quad$ Coop. de CSS & 767631,37 & 13,63 & 877678,2 & 9 \\
\hline - UBPC & 0 & 0 & 0 & 0 \\
\hline - OUTROS & 1917,62 & 0,034 & 66061,8 & 5 \\
\hline
\end{tabular}

Fuente: Elaborado por el autor, utilizando los datos de DATABASE. FAOSTAT. 2017. Disponible en:http://www.fao.org/statistics/en/. Acceso el 24/05/2017.

Nde: no determinado.

\section{La organización socioeconómica de la producción agropecuaria en Cuba en el periodo de 1975-1990. Aciertos y desaciertos en la resolución de la cuestión agraria.}

En este ítem destacaremos, en primer lugar, los principales aciertos en la organización socioeconómica de la producción estatal en general y los principales resultados de la producción cooperativa. Posteriormente señalaremos los principales desaciertos ocurridos en este periodo en materia de resolución de la cuestión agraria en el país.Como lo hemos planteado anteriormente, en estaetapafue priorizadala industria azucarera dentro del programa de inversión pública; impulso asociado al proceso de integración económica del país con la comunidad socialista. Se realizaron grandes volúmenes de inversión en la agroindustria cañera y durante este periodo fueron construidosnuevos centrales azucareros con ayuda de los países miembros del CAME y en los cuales más del 60\% de los componentes tecnológicos fueron producidos por las empresas cubanas (Ver Tabla N5). 
Tabla N ${ }^{\circ} 5$

\section{Cuba- Principales inversiones en la agroindustria cañera 1975-1989}

\begin{tabular}{|l|c|c|c|}
\hline Centrales Construidos & Año & $\begin{array}{c}\text { Valor } \\
\text { MP4 }\end{array}$ & Capacidad \\
\hline 5 de septiembre & 1981 & 62917 & $600 \mathrm{M@/día}$ \\
\hline Grito de Yara & 1982 & 66604 & $600 \mathrm{M} @$ día \\
\hline Jesús Suarez Gallol & 1983 & 60860 & $600 \mathrm{M} @$ día \\
\hline Batalla Sta Clara & 1986 & 63198 & $600 \mathrm{M} @$ día \\
\hline Majibacoa & 1987 & 67940 & $600 \mathrm{M} @$ día \\
\hline Mario Muñoz & 1987 & 67280 & $600 \mathrm{M@/día}$ \\
\hline
\end{tabular}

Fuente: Anuario Estadístico de Cuba de 1987

Además, la evolución de la dinámica de los rendimientos agrícolas y la producción de azúcar en esos años presenta una variación positiva conforme lo indica la Tabla 6. Observamosque los rendimientos agrícolas aumentaron de 44,4 toneladas/hectáreas en 1975 a 60,0 toneladas/hectáreas en 1989 (aumento de más de un tercio), no sucediendo lo mismo con el rendimiento industrial que no pasó de 1 tonelada/hectárea constituyéndose en el principal factor de ineficiencia de la agroindustria cañera.Asimismo, cuando los comparamos con los rendimientos agroindustriales delos principales productores de azúcar a nivel mundial, apreciase que el nivel de rendimiento obtenido (durante el período) fue muy bajo. Países como África del Sur, Australia e Indonesia, obtuvieron rendimientos agroindustriales superiores. (Ver Tabla $\mathrm{N}^{\circ} 6$.)

\section{Tabla $\mathrm{N}^{\circ} 6$ \\ Rendimientos agrícolas, industriales y agroindustriales obtenidos con la producción de caña de azúcar en algunos países en 1975 y 1989.}

\begin{tabular}{|l|c|c|c|c|c|c|}
\hline \multicolumn{1}{|c|}{ Paises } & $\begin{array}{c}\text { Rendimiento } \\
\text { Agricola en } \\
\text { ton. caña/ha }\end{array}$ & $\begin{array}{c}\text { Rendimiento } \\
\text { Industrial en } \\
\text { ton. Azicar/ } \\
\text { ton. cana }\end{array}$ & $\begin{array}{c}\text { Rendimiento } \\
\text { Agroindustria } \\
\text { l en ton. } \\
\text { azicar/há }\end{array}$ & $\begin{array}{c}\text { Rendimiento } \\
\text { Agricola en } \\
\text { ton. cana/ha }\end{array}$ & $\begin{array}{c}\text { Rendimiento } \\
\text { Industrial en } \\
\text { ton. Azuicar/ } \\
\text { ton. cana }\end{array}$ & $\begin{array}{c}\text { Rendimiento } \\
\text { Agroindustria } \\
\text { l en ton. } \\
\text { azicar/há }\end{array}$ \\
\hline África -Sur & 90,11 & 0,116 & 10,50 & 71,90 & 0,120 & 8,66 \\
\hline México & 72,01 & 0,073 & 5,29 & 71,67 & 0,083 & 6,01 \\
\hline Argentina & 53,20 & 0,086 & 4,61 & 59,74 & 0,093 & 5,60 \\
\hline Brasil & 46,47 & 0,068 & 3,19 & 62,02 & 0,033 & 2,10 \\
\hline Colómbia & 81,3 & 0,048 & 3,85 & 82,34 & 0,054 & 4,46 \\
\hline Indonesia & 124,56 & 0,078 & 9,80 & 78,87 & 0,071 & 5,64 \\
\hline Australia & 85,51 & 0,133 & 11,40 & 86,0 & 0,137 & 11,80 \\
\hline Cuba & 44,40 & 0,10 & 4,40 & 60,0 & 0,100 & 6,00 \\
\hline
\end{tabular}

Fuentes: Statistical Yearbook. United Nations. 1975; Anuario Estadístico de Cuba. 1987-1998; Anuario Estadístico de A Latina y El Caribe. 1975, 1980, 1985, 1989.FAOSTAT. Statistic. DATABASE. FAO. 2000. 
Polis, Revista Latinoamericana, $N^{\circ}$ 47, 2017

La producción media de azúcar, en el período mencionado, fue de 7 millones de toneladas aproximadamente. En 1975 la producción alcanzó6,4 millones de toneladas y en 1989 selogró 8,1 millones de toneladas, lo que representó un aumento de 2 millones en esta etapa (Ver Tabla $\mathrm{N}^{\circ} 7$.)Esta producción fue comercializada a nivel internacional con contratos de largo plazo firmados con los países miembros del CAME;estopermitió (con el uso de créditos "favorables") obtener el financiamiento necesario para la industrialización del país.Esta forma de comercio administrado, que presuponía precios fijos a largo plazo con el objetivo de facilitar la planificación productiva, protegía a la economía de las fluctuaciones de la coyuntura internacional; esto aunque el país quedara aislado de la competencia de los mercados. La relación de intercambio establecida con la URSS en este período supera a la correspondiente a precios internacionales, calculándose un ingreso $50 \%$ más elevado del que se podría haber obtenido en caso de venderse el azúcar a los precios existentes en el mercado internacional (Ver Tabla $\mathrm{N}^{\circ}$ 7.)

\section{Tabla $\mathrm{N}^{\circ} 7$}

Cuba: Producción, exportación y precios de exportación del azúcar.

\begin{tabular}{|c|c|c|c|c|}
\hline \multirow[b]{2}{*}{ Año } & \multicolumn{2}{|c|}{ Miles de toneladas } & \multicolumn{2}{|c|}{$\begin{array}{l}\text { Precios del azúcar } \\
\text { (en centavos de dólar por } \\
\text { libra FOB) }\end{array}$} \\
\hline & $\begin{array}{l}\text { Producción de } \\
\text { azúcar. }\end{array}$ & $\begin{array}{l}\text { Exportaciones de } \\
\text { azúcar. }\end{array}$ & $\begin{array}{c}\text { Acuerdos URSS - } \\
\text { CUBA }\end{array}$ & $\begin{array}{l}\text { Mercado } \\
\text { Mundial }\end{array}$ \\
\hline 1975 & 6,427 & 5,744 & 26,36 & 20,37 \\
\hline 1976 & 6,151 & 5,764 & 27,41 & 11,51 \\
\hline 1977 & 6,953 & 6,238 & 26,94 & 8,10 \\
\hline 1978 & 7,662 & 7,197 & 36,71 & 7,82 \\
\hline 1979 & 7,800 & 7,199 & 37,17 & 9,65 \\
\hline 1980 & 6,805 & 6,170 & 47,39 & 28,15 \\
\hline 1981 & 7,926 & 7,055 & 35,10 & 16,8 \\
\hline 1982 & 8,039 & 7,727 & 39,00 & 8,38 \\
\hline 1983 & 7,460 & 7,011 & 46,00 & 8,56 \\
\hline 1984 & 7,783 & 7,007 & 44,00 & 5,18 \\
\hline 1985 & 7,889 & 7,206 & 45,00 & 4,05 \\
\hline 1986 & 7,467 & 6,697 & 41,80 & 6,05 \\
\hline 1987 & 7,232 & 6,479 & 41,90 & 6,76 \\
\hline 1988 & 7,579 & 6,975 & 41,90 & 10,19 \\
\hline 1989 & 8,119 & 7,119 & 41,90 & 12,81 \\
\hline 1990 & & & & \\
\hline
\end{tabular}

Fuente: CEPAL.

En este periodo, las exportaciones se concentraron fundamentalmente en la producción de azúcar (ver Figuras $N^{\circ} 1$ y $\mathrm{N}^{\circ} 2$ ), producto del poco valor agregado (no se exportaba azúcar refinada) y aproximadamente 85\% de este total se dirigía principalmente a los países miembros del CAME. Por otro lado, Cuba cubría gran parte de sus necesidades de alimentos, 
combustibles, insumos para la agricultura y bienes de capital con importaciones. Asimismo, en este período incrementase la dependencia económica del país con relación al intercambio comercial y el azúcar continúo siendo el principal producto de exportación.

\section{Figura $N^{\circ} 1$}

\section{Cuba: Evolución de las exportaciones 1975-1989 en (\%).}

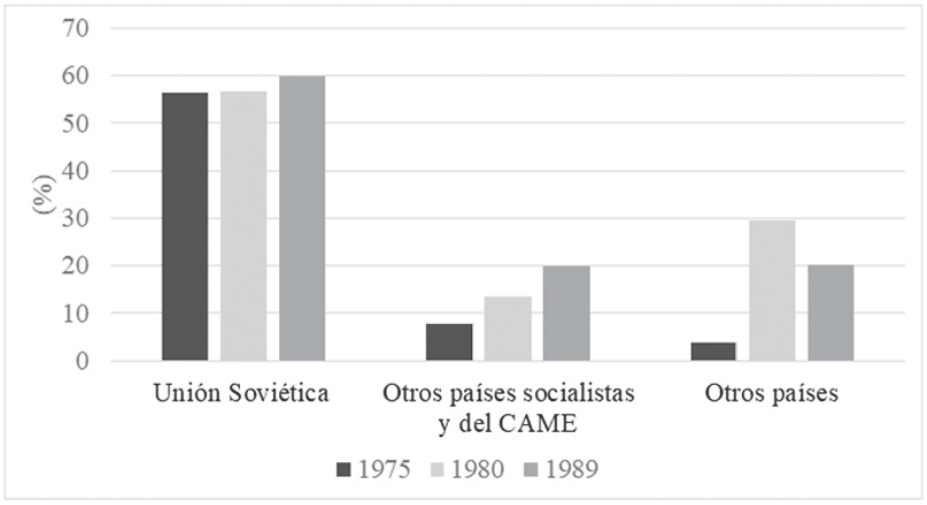

Fuente: CEPAL

\section{Figura $\mathrm{N}^{\circ} 2$}

Cuba: Evolución de las exportaciones azucareras y no azucareras 1980-1989 (\%)

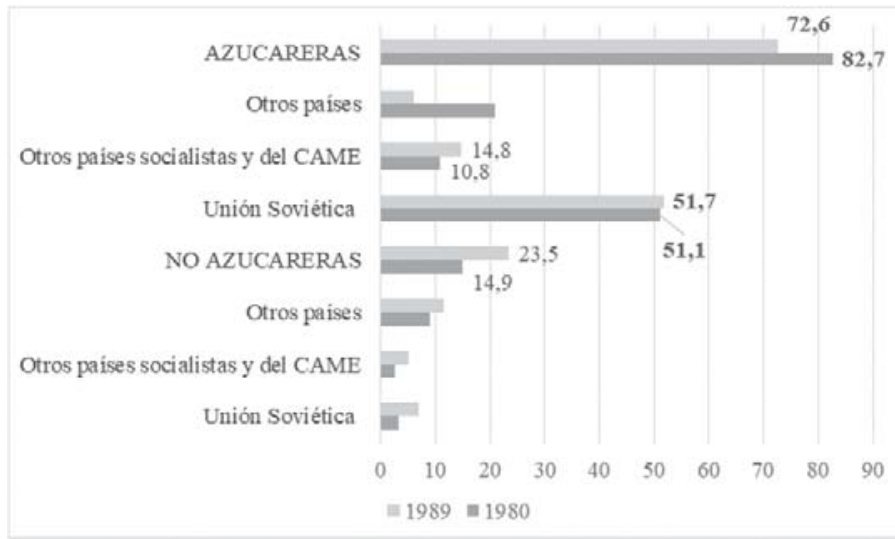

Fuente: CEPAL 
Polis, Revista Latinoamericana, $N^{\circ} 47,2017$

La inserción en el sistema socialista de acumulación reforzó el hecho de que la economía cubana fuera abierta y de ahí la balanza comercial durante el período mostró un crecimiento continuo del déficit comercial, que de 166 millones de peso en 1975 llego a 2.732 millones de pesos en 1989. Ver Tabla N8.

\section{Tabla $\mathbf{N}^{\circ} 8$ \\ Cuba: Exportación, Importación y Saldo Comercial en (millones de pesos) 1975-1990}

\begin{tabular}{|l|r|r|r|r|}
\hline & $\mathbf{1 9 7 5}$ & $\mathbf{1 9 8 0}$ & $\mathbf{1 9 8 5}$ & $\mathbf{1 9 8 9}$ \\
\hline \multicolumn{1}{|c|}{ Exportación Total } & 2,947 & 3,967 & 5,992 & 5,392 \\
\hline Unión Soviética & 1,661 & 2,253 & 4,482 & 3,231 \\
\hline Resto de los países socialistas y de CAME & 341 & 534 & 850 & 1,075 \\
\hline Resto del mundo & 945 & 1,18 & 660 & 1,086 \\
\hline \multicolumn{1}{|c|}{ Importación Total } & $\mathbf{3 , 1 1 3}$ & $\mathbf{4 , 6 2 7}$ & $\mathbf{8 , 0 3 5}$ & $\mathbf{8 , 1 2 4}$ \\
\hline Unión Soviética & 1,25 & 2,904 & 5,419 & 5,522 \\
\hline Resto de los países socialistas y de CAME & 354 & 709 & 1,351 & 1,411 \\
\hline Resto del mundo & 1,509 & 1,014 & 1,265 & 1,191 \\
\hline \multicolumn{1}{|c|}{ Saldo Comercial Total } & -166 & -660 & $-2,043$ & $-2,732$ \\
\hline Unión Soviética & 411 & -651 & -937 & $-2,291$ \\
\hline Resto de los países socialistas y de CAME & -13 & -175 & -501 & -336 \\
\hline Resto del mundo & -564 & 166 & -605 & -105 \\
\hline
\end{tabular}

Fuente: CEPAL, con base en datos de 1os Anuarios Estadísticos de Cuba y del Comité Estatal de Estadísticas.

En relación con las cooperativas de producción agropecuaria, los resultados económicos alcanzados en el periodo analizadopor estas nuevas formas de organización fueron positivos. Aproximadamente el 78\% de las mismas fueron rentables o alcanzaron resultados económicos eficientes, fundamentalmente las cooperativas de producción agropecuarias especializadas en la producción de caña de azúcar como se refleja en la Tabla $\mathrm{N}^{\circ} 9$. 
Tabla $N^{\circ} 9$

Resultados económicos de las CPA 1987-1992.

\begin{tabular}{|c|c|c|c|c|c|c|c|c|c|c|c|c|}
\hline \multirow[t]{2}{*}{$\mathrm{CPA}$} & \multicolumn{2}{|c|}{1987} & \multicolumn{2}{|c|}{1988} & \multicolumn{2}{|c|}{1989} & \multicolumn{2}{|c|}{1990} & \multicolumn{2}{|c|}{1991} & \multicolumn{2}{|c|}{1992} \\
\hline & Cant. & $\%$ & Cant. & $\%$ & Cant. & $\%$ & Cant. & $\%$ & Cant. & $\%$ & Cant. & $\%$ \\
\hline $\begin{array}{l}\text { Total } \\
\text { elaboran } \\
\text { balances eco. }\end{array}$ & 1377 & 100 & 1357 & 100 & 1331 & 100 & 1339 & 100 & 1260 & 100 & 1190 & \\
\hline Cañeras & 423 & & 428 & & 414 & & 407 & & 396 & & 390 & \\
\hline No Cañeras & 954 & & 929 & & 917 & & 932 & & 864 & & 800 & \\
\hline $\begin{array}{lr}\text { Costo por } \\
\text { peso de } \\
\text { producción. }\end{array}$ & 0,85 & & 0,77 & & 0,75 & & 0,75 & & 0,76 & & 0,74 & \\
\hline Cañeras & 0,83 & & 0,76 & & 0,74 & & 0,73 & & 0,73 & & 0,78 & \\
\hline No Cañeras & 0,86 & & 0,77 & & 0,75 & & 0,76 & & 0,79 & & 0,7 & \\
\hline Rentables & 896 & 65 & 1165 & 86 & 1055 & 79 & 1065 & 80 & 966 & 77 & 1008 & 85 \\
\hline Cañeras & 300 & 71 & 450 & 105 & 380 & 92 & 373 & 92 & 359 & 91 & 345 & 88 \\
\hline No Cañeras & 596 & 62 & 715 & 77 & 675 & 74 & 692 & 74 & 607 & 70 & 663 & 83 \\
\hline
\end{tabular}

Fuente: NOVA A.Las cooperativas agropecuarias en Cuba: 1959-presente. (2011).

Al mismo tiempo, llama poderosamente la atención en este periodo el hecho de que los resultados positivos alcanzados por las CPA contrastaban con los resultados negativos obtenidos por las grandes empresas agrícolasestatales. Como se manifiesta en la Tabla N¹0, en el año 1990, solamente el 27 \% de las empresasestatales agrícolas eran rentables; situación que empeoró a partir dela crisis económica de los años 90.En la práctica, el modelo cooperativo reveló sus ventajas frente al modelo estatal, aunque no logró un éxito semejante entre los pequeños productores.

\section{Tabla $\mathrm{N}^{\circ} 10$ \\ Resultados económicos de las empresas estatales agrícolas (no cañeras).}

\begin{tabular}{|l|c|c|c|c|c|c|c|c|c|c|}
\hline \multirow{2}{*}{$\begin{array}{c}\text { Empresas } \\
\text { agicolas } \\
\text { estatales }\end{array}$} & \multicolumn{2}{|c|}{1986} & \multicolumn{2}{c|}{1987} & \multicolumn{2}{c|}{1988} & \multicolumn{2}{c|}{1989} & 1990 \\
\cline { 2 - 12 } & Cant. & $\%$ & Cant. & $\%$ & Cant. & $\%$ & Cant. & $\%$ & Cant. & \% \\
\hline Rentables & 170 & $\mathbf{3 9}$ & 132 & $\mathbf{3 3}$ & 132 & $\mathbf{3 3}$ & 119 & $\mathbf{3 1}$ & 100 & $\mathbf{2 7}$ \\
\hline No rentables & 257 & 61 & 266 & 67 & 257 & 66 & 263 & 69 & 266 & 73 \\
\hline
\end{tabular}

Fuente: Nova A. (2011).

O sea, el proceso de organización de la producción agropecuaria cubana en este periodoestuvo caracterizado por el predominio de una empresa estatal de gran escala de producción (fenómeno acuñado por algunos autores cubanos como "gigantismo empresarial") y elevada centralización en la gestión administrativa.Con la introducción del SDPE, esta tendencia al gigantismo de las entidades agrícolas estatales (que no siempre 
respondía al concepto de economías de escala y a una base material y técnica de sustentación), termino por influenciar al sector cooperativo. (Ver Tabla $\mathrm{N}^{\circ} 11$ ).

Tabla $N^{\circ} 11$

Tamaño medio de la empresa estatal agropecuaria y las cooperativas de producción agropecuarias en hectáreas.

\begin{tabular}{|l|c|c|c|c|}
\hline Cultivo/Actividad & \multirow{2}{*}{$\begin{array}{c}\text { Empresa } \\
\text { Estatal } \\
\text { (hectáreas) }\end{array}$} & \multicolumn{2}{|c|}{ CPA } & $\begin{array}{c}\text { Relación en } \\
\text { Emp. } \\
\text { Estatal/CPA } \\
\text { (veces) }\end{array}$ \\
\cline { 4 - 5 } & & & $\begin{array}{c}\text { Área por } \\
\text { cooperativista }\end{array}$ & 14,5 \\
\hline Cañera & 13110 & 903 & 13 & 8,8 \\
\hline Cultivos Varios & 4276 & 481 & 9 & 18,65 \\
\hline Cítricos y frutales & 10822 & 580 & 14 & 621,6 \\
\hline Arroz & 32760 & 52,7 & 15 & 39,72 \\
\hline Ganadería & 24865 & 626 & 23 & 5,5 \\
\hline Tabaco & 2778 & 505 & 9 & $\mathrm{ND}$ \\
\hline Café & $\mathrm{ND}$ & 459 & 15 & \\
\hline
\end{tabular}

Fuente: Nova A. (2003) La UBPC y el cooperativismo en la agricultura cubana 1993-2001.

Es necesario destacar que este modelo organizacional utilizado en Cuba se fundamentaba en una agricultura industrial, altamente consumidora de insumos con una importante dotación de inversión y equipamiento por hectárea, y al mismo tiempo dependiente de grandes recursos energéticosexternos. En la década de los años ochenta - particularmente en la segunda mitad - este modelo comenzó a mostrar signos de agotamiento.Varios indicadores económicos en el país reflejaban la realidad de esta problemática (Ver Tablas 12 y 13).El Producto Interno Bruto en el periodo presentó un crecimiento positivo de aproximadamente $177 \%\left[\left(19201,8_{(1999)} / 10718_{(1975)}\right) * 100=177 \%\right]$, pero debemos destacar que en 1987 por primera vez cayó el Producto Interno Brutoy la participación de la industria manufacturera en -3,5\% y $-3.1 \%$ respectivamente, esto si tomamos como base de análisis el año 1986.

En relación con el uso de los recursos o factores de producción, el consumo de fertilizantes y el parque de tractores se incrementaron en $192 \%$ y $142 \%$ respectivamente, lo que explica el aumento de la productividad del trabajo y la estabilización de la fuerza de trabajo agropecuaria en el periodo.

La producción de alimentos crece a tasas más bajas que las planificadas y el número de cabezas de ganado disminuyó considerablemen- 
te; o sea, la evolución desfavorable de la oferta interna de alimentos y la necesidad de mantener los niveles de consumo básico de la población llevaron a que en 1989 las importaciones de alimentos aumentaran en $11 \%$, las de bienes intermediarios y de capital crecieron moderadamente aproximadamente 7\%, concentrándose en insumos agroquímicos para el programa alimentario, materiales de construcción y piezas de repuestos y equipos de transporte. De hecho, se presentaron dificultades y escasez de divisas para el abastecimiento de materias primas y bienesde capital.

Tabla $\mathrm{N}^{\circ} 12$

Cuba: Indicadores seleccionados del crecimiento económico y del uso de los recursos en la producción agropecuaria 1975-1990

\begin{tabular}{|l|c|c|c|c|}
\hline \multicolumn{1}{|c|}{ Indicadores selecionados } & $\mathbf{1 9 7 5}$ & $\mathbf{1 9 8 0}$ & $\mathbf{1 9 8 5}$ & $\mathbf{1 9 9 0}$ \\
\hline PIB (Millones de pesos) & 10718 & 13068,6 & 19201,8 & 19008,3 \\
\hline Crecimiento prod. Alimentos (Tasas anuales) & $-4,8$ & 3,5 & 1,4 & 3,3 \\
\hline Consumo de Fertilizantes (Toneladas) & 302400 & 529500 & 585300 & 580000 \\
\hline Mecanización(hectáreas tierra cultivables por tractor) & 57 & 47 & 48 & 43 \\
\hline Parque de tractores (Unidades en servicio) & 54851 & 68300 & 68585 & 77800 \\
\hline Existencia de ganado vacuno (miles de cabezas) & 5450 & $5114_{(1982)}$ & 5020 & 4920 \\
\hline Mano de obra empleada en la agropecuaria (miles) & $685_{(1976)}$ & 624 & 572 & $690\left(_{(1989)}\right.$ \\
\hline
\end{tabular}

Fuente: CEPAL y Anuarios Estadísticos de Cuba 1976, 1982, 1989.

Además, el consumo de la población y la dieta alimenticia que fue objeto de atención prioritaria por parte de las autoridades en este periodo, se resintió y la ingesta de calorías y proteínas por habitante registró el nivel más bajo del decenio de 1980. Este deterioro de la alimentación se debió a que disminuyó la producción de algunos rubros básicos de la dieta, como pescado, hortalizas, tubérculos y frutas derivado de lo anteriormente explicado. 
Tabla $\mathrm{N}^{\circ} 13$

Cuba: Indicadores del consumo por habitante 1980-1989.

\begin{tabular}{|c|c|c|c|}
\hline & 1980 & 1985 & 1989 \\
\hline \multicolumn{2}{|l|}{ Productos alimenticios } & & \\
\hline \multicolumn{2}{|l|}{ Calorías (unidades/día) } & $-0,9$ & $-3,4$ \\
\hline \multicolumn{2}{|l|}{ Proteínas (gramos/día) } & 0,1 & $-3,3$ \\
\hline Carne & 8,7 & 3,4 & $-2,7$ \\
\hline Pescado & 16 & 8,3 & -13 \\
\hline Leche y Derivados & 1,3 & $-1,3$ & $-0,4$ \\
\hline Huevos (unidades) & 17,4 & $-3,2$ & 1,7 \\
\hline Cereales & 4,9 & $-1,9$ & $-3,5$ \\
\hline Grasas & 5,5 & 2,3 & $-3,9$ \\
\hline Hortalizas & 39,1 & 3,8 & $-9,9$ \\
\hline Tubérculos y raíces & 6,2 & $-3,3$ & $-7,5$ \\
\hline Frutas & 27,5 & 10,2 & $-12,1$ \\
\hline Frijol & 5,9 & 0,8 & 3,3 \\
\hline Azúcar & 3,6 & $-3,1$ & $-2,8$ \\
\hline
\end{tabular}

Fuente: CEPAL

Entre los principales desaciertos sucedidos en esta etapa debemos destacar los siguientes:

a) Desde inicios de los años ochenta, se perciben algunos efectos negativos en la implementación de objetivos estratégicos contenidos en la política económica trazada e implementada a través del SDPE, emergiendo conductas economicistas y mercantilistas en 1982. En este periodo las empresas estatales abusaron en el uso y distribución del pago de estímulos materiales tanto individuales (primas) como colectivos (premios) sin la debida correspondencia con los resultados productivos realmente alcanzados. En el caso del pago de primas individuales, la fuente de financiamiento era el presupuesto del gobierno y en el segundo (pago de premios), las ganancias empresariales.Dicho de otra forma,los incentivos materiales y las herramientas mercantiles retrocedían a la economía cubana al capitalismo, corrompían a los trabajadores y a los directivos y diluían en el fervor revolucionario

Así, en 1986 comienza un proceso de rectificación de errores y tendencias negativas con el propósito de sanear el proceso de desarrollo económico y social de elementos que retardaban y frenaban su normal desempeño y que tenían repercusión en todos los planos de la vida económica y social del país, una vez que obstaculizaban la interrelación necesaria 
que debía existir entre la satisfacción de los intereses individuales y los intereses de toda la sociedad.

Según Fidel Castro:

“(...) Es un error creer que el socialismo puede ser construido con incentivos materiales (...). El socialismo debe ser construido con consciencia e incentivos morales (...). En la búsqueda de la eficiencia económica hemos creado el caldode cultivo para numerosos vicios, deformidades y corrupción”(Castro 5 , 1986, p. 3).

Estaba claro que el SDPE mostraba los límites de la planificación y la dificultad de aumentar la eficiencia sin contaminar el sistema con la introducción de mecanismos de mercado. Sin embargo, la crítica al SDPE protagonizada por el máximo líder de la revolución, llevó a una recentralización de las decisiones económicas.

b) Debemos destacar elcontexto internacional desfavorable en que se desempeñó la economía cubana en esta segundamitad de los años ochenta ante el progresivo declive económico de los países integrantes delCAME. De hecho, se presentaron dificultades para el abastecimiento de materias primas y bienesde capital y se deterioró la relación de los precios de intercambio. A título de ejemplo, puedemencionarse que la extinta Unión Soviética pagó la libra de azúcar cubano a 41.90 centavos en 1989 frente a 45 centavos en 1985, una disminución del 7\%.

c) El colapso del campo socialista europeo y la desintegración de la Unión Soviética eliminaron abruptamente los mercados tradicionales de exportación de productos cubanos, las fuentes de adquisición de bienes y servicios fundamentales para el funcionamiento productivo.La isla quedó así sin sus mercados y posibilidades externas de financiamientotradicionales por lo que disminuyó su capacidad de importar, con deformaciones en su estructuraproductiva y rezagados mecanismos de gestión empresarial, todo lo cual configuró un cuadro debaja competitividad en un nuevo y desconocido escenario internacional. Además, las pequeñasdimensiones del mercado interno y la escasez de petróleo decretan una vulnerabilidad externaque, en las condiciones dadas impidieron amortiguar a corto plazo los efectos negativos de los choquesexternos.

d) La poca valorización del trabajo agrícola y la falta de expectativas que ofrecían las comunidades rurales a una población que aumentaba año tras año sus niveles de cultura y educación, hicieron de los centros urbanos sus principales atractivos, dando, de esta forma, origen a un verdadero proceso de descampesinización que se reflejó en saldos migratorios negativos, y pérdidas de la población rural.

e) Según Guevara (2009) el sistema de normas aplicadas en la agricultura estatal, lejos de ser un mecanismo para el incremento incesante de la productividad del trabajo obstaculizaba este proceso, incidiendo desfavo- 
rablemente en el sentimiento de propietario colectivo de medios de producción y en la elevada fluctuación de la fuerza de trabajo calificada.El modelo de organización de la producción agropecuaria utilizado a lo largo de este periodo, presentó evidentes síntomas de insostenibilidad económica y ecológica.Siendo que en la actualidad aproximadamente cuatro millones dehectáreas están afectadas por problemas de salinización y erosión. (Ver Figura $\mathrm{N}^{\circ} 3$ )

\section{Figura $\mathrm{N}^{\circ} 3$ \\ Agroproductividad de los suelos de Cuba}

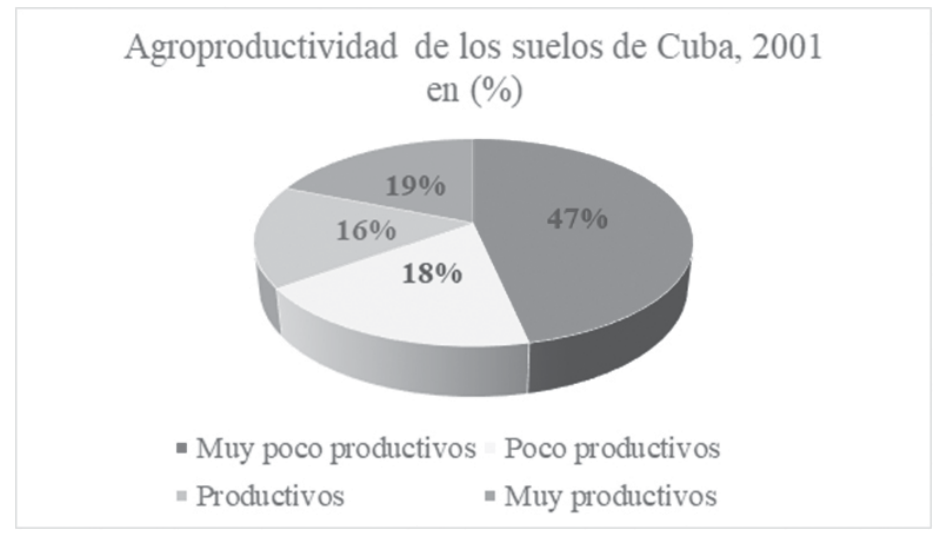

Fuente: Anuario Estadístico de Cuba de 2011.

\section{Crisis de la grande empresa agropecuaria estatal socialista y la necesidad de una tercera reforma agraria en 1993}

La desaparición del campo socialista y la agudización del bloqueo económico obligó al estado cubano a introducir un conjunto de modificaciones estructurales en el modelo económico del país y en la agropecuaria en particular. Debemos esclarecer que estas reformas aplicadas a partir de los años 90, por su esencia y contenido son totalmente distintas a las de contenido neoliberal que en ese mismo periodo eran aplicadas en América Latina, porque en el caso de Cuba estuvieron dirigidas a mantener el empleo y defender los logros sociales alcanzados por la revolución en esos últimos 30 años.

La Reforma Agraria,puesta en vigor a partir de 1993, significó el tránsito hacia un nuevo modelo agrario cuyo objetivo principal sería resolver el problema de la soberanía alimenticia, (entendida como la necesidad de la nación de mantener y desarrollar su propia capacidad de producir alimentos 
que son decisivos para la seguridad alimentaria nacional y comunitaria, respetando la diversidad cultural y la diversidad de los métodos de producción). La principal diferencia entre esta nueva forma de tenencia de la tierra y las reformas agrarias de 1959 y 1963 radica en que la presente reforma (la de 1993) está basada en el ajuste estructural de la propiedad estatal mediante la parcelación de la tierra bajo diferentes regímenes: a) en régimen cooperativo (fórmula dominante); b) en régimen de autogestión participativa, en las granjas no cooperativizadas; c) en régimen individual a favor de personas y familias; y d) en régimen privado empresarial de parcelación, ya las reformas anteriores defendieron la socialización de la gran propiedad privada agrícola y del campesinado.Según Figueroa y Averoff (2001) esta nueva reforma agraria fue resultado de una iniciativa de la dirección política central del país, y no el producto de imperativos políticos, o de reivindicaciones de trabajadores y demás productores agrícolas.

Así, el Gobierno y el Estado cubano decretan,a partir del mes de septiembre de 1993, la creación de las Unidades Básicas de Producción Cooperativa (UBPC), las cuales surgen tomando como fundamento normativo el funcionamiento de las CPA y como base económica el patrimonio fomentado por las anterioresestructuras de producción estatal. Es importante destacar que el Gobierno y el Estado cubano, consciente de que las grandes empresas agropecuarias estatales presentaron resultados económicos negativos, profundizados por la crisis económica de los años 90, optó por las experiencias o formas cooperativas existentes en el país (como las CPA y las CCS)una vez que éstasestaban mejor preparadas que la empresa estatal para trabajar y funcionar bajo condiciones de escases de recursos. $O$ sea, el nuevo modelo utilizado en la conformación de las UBPC fundamentase en la trayectoria, la experiencia y los resultados positivos alcanzados por las Cooperativas de Producción Agropecuaria surgidas en 1976.

Por tanto esta nueva reforma agraria inicia una nueva etapa en el desarrollode la economía cubana donde se promueve la descentralización o desestatización del proceso de gestión y funcionamiento de la industria agropecuaria cubana, considerándose la creación de las UBPC como la transformación más revolucionaria que se haproducido en el agro cubano después de la promulgación de las $1^{\mathrm{a}}$ y $2^{\mathrm{a}}$ Leyes de ReformaAgraria y constituyen una nueva forma de organización de la producción donde seintegran obreros agrícolas para el trabajo colectivo, recibiendo la tierra en usufructo ysiendo propietarios de los restantes medios y de la producción.

Entre las principales características de las UBPC tenemos:

- Venderán su producción al Estado.

- Pagarán el aseguramiento técnico-material.

- Operarán cuentas bancarias.

- Comprarán, a crédito, los medios fundamentales de producción. 
• Elegirán en colectivo su dirección y ésta rendirá cuenta periódicamente.

- Cumplirán las obligaciones fiscales como contribución a los gastos de la nación. Sus principios de funcionamiento son:

- Producirán vinculación del hombre al área.

- Buscarán el autoabastecimiento de los obreros y su familia y mejoramiento de las condiciones de vida.

- Promoverán los ingresos de los trabajadores asociados rigurosamente a la producción.

- Desarrollarán ampliamente la autonomía de la gestión y la administración de sus recursos haciéndose autosuficientes en el orden productivo.

En realidad, las Unidades Básicas de Producción Cooperativa representan un nuevo arquetipo de cooperativas de tipo empresarial y están integradas por trabajadores estatales asalariados procedentes de las empresas estatales agropecuarias. Es decir, con la creación de este nuevo tipo de cooperativa, por iniciativa e decisión del gobierno revolucionario, comienza un proceso singular de desestatización de la posesión de la tierra y de los activos estatales. Así, los “antiguos” trabajadores asalariados estatales, se convierten en trabajadores-propietarios colectivos con intereses propios de tal categoría.En este nuevo contexto debemos tener claro que las UBPC creadas son algo más que empresas: constituyen una comunidad económico-social integrada en el medio rural. Se diferencian de las empresas mercantiles convencionales (cuyo objetivo principal es la maximización de la tasa de ganancia), en que, sin dejar de perseguir un interés de beneficio, están obligadas a tener otros objetivos de índole social-comunitaria.

La satisfacción de ambos aspectos es un concepto básico para entender su lógica.Debemos tener presente,que esta tercera reforma agraria (y la creación de las UBPC) no puede verse como un hecho aislado, sino que forma parte del conjunto de medidas tomadas para lograr el reordenamiento de la economía cubana, medidas como: la apertura al capital extranjero, el saneamiento de las finanzas internas, la creación del mercado agropecuario y la entrega de tierras enusufructo, entre otras. Con esta nueva forma de organización del proceso de producción agropecuario, (las UBPC), permiten eliminar preliminarmente el problema del gigantismo empresarial creado con anterioridad al disminuir el tamaño promedio por unidad de hectárea, como refleja la Tabla $\mathrm{N}^{\circ} 14$. 
TablaN 14

Tamaño medio de la empresa estatal agropecuaria y las unidades básicas de producción agropecuarias en hectáreas.

\begin{tabular}{|l|c|c|c|}
\hline Culturas producidas & $\begin{array}{c}\text { Empresasestatales en } \\
\mathbf{1 9 9 0}\end{array}$ & UBPC en 1993 & $\begin{array}{c}\text { Relación en Emp. } \\
\text { Estatal/UBPC } \\
\text { (veces) }\end{array}$ \\
\hline Caña de azúcar & 13110 & 1190 & 11,01 \\
\hline Cultivos varios & 4276 & 456 & 9,37 \\
\hline Cítricos y frutales & 10822 & 100 & 108,22 \\
\hline Arroz & 32760 & 5132 & 6,38 \\
\hline Tabaco & 2778 & 241 & 11,52 \\
\hline Pecuarias & 24865 & 1595 & 15,5 \\
\hline
\end{tabular}

O sea, con la creación de las UBPC, junto con el funcionamiento de las CPAs y las CCS, Cuba definió el cooperativismo (manteniendo así a la propiedad colectiva como la forma de propiedad predominante) como la base fundamental de su sistema económico empresarial agropecuario, reconfigurando la forma de tenencia de la tierra, siendo que actualmente el $\mathbf{5 4 \% ( d e ~ l a s ~ t i e r r a s ) ~ e s t a ́ ~ e n ~ m a n o s ~ d e l ~ E s t a d o ~ y ~ e l ~} \mathbf{4 6 \%}$ restante es propiedad no estatal. En estos momentos, en el sector agropecuario participan cinco tipos de entidades productivas: las UBPC, CPA, CCs, productores privados y el sector estatal, ver Tabla $\mathrm{N}^{\circ} 15$.

\section{TablaN ${ }^{\circ} 15$}

\section{Cuba. Distribución y uso de la tierra según la forma de propiedad en 2013.}

\begin{tabular}{|c|c|c|c|c|c|c|c|c|c|c|c|}
\hline & \multicolumn{10}{|c|}{ Superficie en hectáreas. } & \\
\hline & \multicolumn{3}{|c|}{ Estatal } & \multicolumn{8}{|c|}{ No estatal } \\
\hline CONCEPTO & Total & Estatal & $(\%)$ & Total & (\%) & UBPC & (\%) & CPA & $(\%)$ & $\begin{array}{c}\text { CCS y } \\
\text { Privados }\end{array}$ & $(\%)$ \\
\hline Total & $10.988,4$ & $5.932,1$ & 54,0 & $5.056,3$ & 46,0 & $1.952,0$ & 38,6 & 614,3 & 12,1 & $2.490,0$ & 49,2 \\
\hline $\begin{array}{l}\text { Superficie } \\
\text { agricola }\end{array}$ & $6.342,4$ & $1.851,7$ & 29,2 & $4.490,7$ & 70,8 & $1.677,5$ & 37,4 & 521,5 & 11,6 & $2.291,7$ & 51,0 \\
\hline $\begin{array}{l}\text { Superficie } \\
\text { cultivada }\end{array}$ & $2.645,8$ & 471,8 & 17,8 & $2.174,0$ & 82,2 & 851,3 & 39,2 & 264,9 & 12,2 & $1.057,8$ & 48,7 \\
\hline $\begin{array}{l}\text { Superficie no } \\
\text { agricola }\end{array}$ & $4.646,0$ & $4.080,4$ & 87,8 & 565,5 & 12,2 & 274,5 & 48,5 & 92,8 & 16,4 & 198,3 & 35,1 \\
\hline
\end{tabular}

Fuente: Anuario Estadístico de Cuba 2013.

Debemos destacar que, en la actualidad,de estas entidades productivas las más eficientes son las CCS y el sector privado, las cuales producen aproximadamente más del $\mathbf{6 0} \%$ de la producción total de alimentos del país utilizando el 23\% y 36\% de la superficie total y de la superficie agrícola respectivamente. Además, son las entidades productivas que registran la menor cantidad de superficie no agrícola y ociosa.Vemos, por lo tanto, que 
Polis, Revista Latinoamericana, $N^{\circ} 47,2017$

esta Tercera Reforma Agraria no ha conseguido resolver el problema de la soberanía alimenticia, una vez que la producción de alimentos del país disminuyó considerablemente entre 2008 y 2013; o sea, la producción agrícola estatal mantiene una tendencia a la disminución en casi todos los productos agrícolas. Al mismo tiempo se observa el considerable aumento del peso del sector no estatal del país en la producción agrícola nacional lo que corrobora lo explicado anteriormente. Ver TablaNº16.

\section{Tabla $\mathrm{N}^{\circ} 16$ \\ Cuba: Producción agrícola por cultivos seleccionados de la agricultura no cañera.Sector estatal y No Estatal 2008 - 2013 (en toneladas)}

\begin{tabular}{|c|c|c|c|c|c|c|}
\hline \multirow[t]{2}{*}{ CULTIVO } & \multicolumn{2}{|c|}{2008} & \multicolumn{2}{|c|}{2013} & \multicolumn{2}{|c|}{ Relación 2013/2008 } \\
\hline & Estado & No Estatal & Estado & No Estatal & Estado & No Estatal \\
\hline Viandas ${ }^{(9)}$ & 318351,096 & 1832348,904 & 184622 & 2054379 & $-42,01$ & 12,12 \\
\hline Tubérculos y raices & 187094,466 & 1205405,534 & 102664 & 1477836 & $-45,13$ & 22,60 \\
\hline De ello: Papa & 59290,872 & 136809,128 & 35529 & 71171 & $-40,08$ & $-47,98$ \\
\hline Boniato & 48768,372 & 326231,628 & 31292 & 365055 & $-35,84$ & 11,90 \\
\hline Malanga & 32772,792 & 207227,208 & 9763 & 176159 & $-70,21$ & $-14,99$ \\
\hline Plátano & 131256,63 & 626943,37 & 81958 & 576543 & $-37,56$ & $-8,04$ \\
\hline Fruta & 51033,366 & 229766,634 & 40311 & 110026 & $-21,01$ & $-52,11$ \\
\hline Vianda & 80223,264 & 397176,736 & 41647 & 466517 & $-48,09$ & 17,46 \\
\hline Hortalizas & 437620,264 & 2001679,736 & 371925 & 2034575 & $-15,01$ & 1,64 \\
\hline De ello: Tomate & 67596,448 & 508303,552 & 41310 & 636690 & $-38,89$ & 25,26 \\
\hline Cebolla & 9615,702 & 118484,298 & 4623 & 122253 & $-51,92$ & 3,18 \\
\hline Pimiento & 8075,024 & 55601,976 & 7257 & 66079 & $-10,13$ & 18,84 \\
\hline Cereales & 76258,892 & 685441,108 & 125762 & 973038 & 64,91 & 41,96 \\
\hline $\begin{array}{l}\text { Arroz cáscara } \\
\text { húmedo }\end{array}$ & 54656,188 & 381343,812 & 110220 & 562380 & 101,66 & 47,47 \\
\hline Maiz & 21602,704 & 304097,296 & 15542 & 410658 & $-28,06$ & 35,04 \\
\hline Leguminosas & 2935,03 & 94264,97 & 5207 & 124593 & 77,41 & 32,17 \\
\hline Frijoles & 2935,03 & 94264,97 & 5207 & 124593 & 77,41 & 32,17 \\
\hline Tabaco & 250 & 21250 & 153 & 23847 & $-38,80$ & 12,22 \\
\hline Cítricos & 243400,26 & 148399,74 & 111610 & 55290 & $-54,15$ & $-62,74$ \\
\hline $\begin{array}{c}\text { De ello: Naranja } \\
\text { dulce }\end{array}$ & 117681,57 & 82718,43 & 63881 & 21229 & $-45,72$ & $-74,34$ \\
\hline Toronja & 123790,462 & 42309,538 & 45526 & 18453 & $-63,22$ & $-56,39$ \\
\hline Limón & 585,396 & 4814,604 & 1458 & 3567 & 149,06 & $-25,91$ \\
\hline Otras frutas & 57567,436 & 680932,564 & 69482 & 855518 & 20,70 & 25,64 \\
\hline De ello: Mango & 16665,524 & 212034,476 & 24835 & 260691 & 49,02 & 22,95 \\
\hline Guayaba & 10275,02 & 116224,98 & 15344 & 109621 & 49,33 & $-5,68$ \\
\hline $\begin{array}{l}\text { Fruta } \\
\text { bomba }\end{array}$ & 12356,244 & 77043,756 & 9278 & 188564 & $-24,91$ & 144,75 \\
\hline Cacao & 60 & 1040 & 20 & 1405 & $-66,67$ & 35,10 \\
\hline
\end{tabular}

Fuente: Anuario Estadisitico de Cuba 2013, 2014, 2015. 
Debemos especificar que las UBPC creadas absorbieron una organización agrícola (las antiguas empresas estatales) diseñadas para operar en condiciones de elevada disponibilidad de recursos técnicos y materiales y en la actualidad operaran en condiciones de escasos recursos como el petróleo, fertilizantes, piensos, medicamentos, etc. Derivado de esa situación, muchas de las dificultades que actualmente confrontan las UBPC tienen su origen en la situación económica existente en el país y no deben ser totalmente atribuidas a esta nueva forma de organización en sí. El Cuadro $\mathrm{N}^{\circ} 1$ destaca las principales ventajas y desventajas en el funcionamiento y concepción de esta nueva forma de producción agropecuaria.

\section{CuadroN 1 \\ Cuba: Principales ventajas y desventajas en el funcionamiento y concepción de las UBPC creadas a partir de 1993.}

\begin{tabular}{|c|c|}
\hline \multicolumn{2}{|c|}{ Principales ventajas y desventajas en el funcionamiento y concepción de las UBPC } \\
\hline Ventajas & Desventajas \\
\hline a) Ligeros aumentos en algunas producciones. & $\begin{array}{l}\text { a) El elevado nivel de compromiso de ventas } \\
\text { establecidos con acopio superior al } 70 \% \text { de } \\
\text { laproducción fundamental. }\end{array}$ \\
\hline $\begin{array}{l}\text { b) Discretos resultados económicos, aunque no } \\
\text { todos atribuibles a la eficienciaeconómica de la } \\
\text { producción fundamental. }\end{array}$ & $\begin{array}{l}\text { b) Los precios pagados por acopio son muy } \\
\text { inferiores a los del Mercado Libre } \\
\text { Agropecuario y por lo general no cubren los } \\
\text { costos }\end{array}$ \\
\hline $\begin{array}{l}\text { c) Reducción del área media de las unidades } \\
\text { productivas de base }\end{array}$ & $\begin{array}{l}\text { c) Falta de autonomia: a las UBPCles definen el } \\
\text { surtido, la cantidad y el destino de lo que } \\
\text { deben producir. }\end{array}$ \\
\hline $\begin{array}{l}\text { d) Elección del personal de dirección por métodos } \\
\text { democráticos }\end{array}$ & $\begin{array}{l}\text { d) L existencia de uns empresa (como nivel } \\
\text { intermedio), que agrupa a las UBPC y que } \\
\text { finslmente es la que orienta, determina y } \\
\text { centraliza las decisiones, desde lo que deben } \\
\text { producir, a quien vender, a que precios, que } \\
\text { insumos recibirán, que inversiones realizar, } \\
\text { entre otros aspectos }\end{array}$ \\
\hline $\begin{array}{l}\text { e) Vinculaciónde los ingresos delos trabajadores } \\
\text { a los resultados económicos. }\end{array}$ & $\begin{array}{l}\text { e) Lo5 recursos los reciben por asignación } \\
\text { centralizada, no existiendo un mercado de } \\
\text { insumo, ni de equipamiento, donde el } \\
\text { productor pueda acudir }\end{array}$ \\
\hline $\begin{array}{l}\text { f) Aumentos del personal directo a la producción } \\
\text { y vinculación del hombre al área }\end{array}$ & $\begin{array}{l}\text { f) Las UBPC ganaderas no pueden acudir con su } \\
\text { producción fundamental (leche y carne), al } \\
\text { Mercado Libre Agropecuario. Las UBPC } \\
\text { arroceras, citricolas y los productores de papa, } \\
\text { tampoco pueden acudir con su producción } \\
\text { fundamentalal Mercado Libre Agropecuario. }\end{array}$ \\
\hline $\begin{array}{l}\text { g) Detenimiento relativo dela fluctuación laboral } \\
\text { y mejoramiento de la disciplins. }\end{array}$ & $\begin{array}{l}\text { g) Presentan dificultades internas en la } \\
\text { contabilidad y la estabilidad de los } \\
\text { cooperativistas. }\end{array}$ \\
\hline $\begin{array}{l}\text { h) Creación de las áreas de auto consumo para los } \\
\text { trabajadores, aunque resultainsuficiente. }\end{array}$ & \\
\hline i) Avances en el uso racional de los recursos. & \\
\hline j) Posibilidad de tomar "algunas" decisiones. & \\
\hline
\end{tabular}

Fuente: Elaborado por el autor apud de Blanca (2010) e Nova (2008). 
Todo parece indicar que una de las principales dificultades encontradas en esta nueva forma de organización radica en la falta de autonomía necesaria para su correcto funcionamiento. Esto ha conllevado que una parte significativa de las UBPC en la actualidad sean deficitarias, desestimulando a los productoresdebido a que no reciben utilidades.

\section{Consideraciones finales}

De todo lo antes expuesto, constatamosla existencia de varios factores negativos tanto del lado de la oferta como de la demanda que inciden negativamente sobre los resultados productivosde las UBPC creadas con la tercera reforma agraria en Cuba.Del lado de la oferta debemos destacar: a) el clima, Cuba, por su posición geográfica es un territorio propenso al paso de ciclones (cada vez más fuertes), la sequía, erosión y salinización de los suelos, afectan directa y negativamente en los resultados productivos alcanzados b) los bajos niveles de productividad del trabajo y rendimientos agrícolas registrados en las UBPC, c) la falta de integración necesaria entre la agroindustria de la caña de azúcar y la base de producción de alimentos con destino al ganado vacuno y porcino, d) la demora en el reconocimiento del papel del mercado (con sus elementos positivos y negativos) dentro de la planificación socialista, e) la falta de un sistema de precios, que renumere satisfactoriamente a los productores nacionales agropecuarios, (en particular, de aquellos productores que sustituyen importaciones) al mismo tiempo que se pagan precios elevadísimos por los productos importados, f) la falta de medidas que descentralicen, la comercialización y eliminen el monopolio del Acopio Estatal y g)la escasa integración científico/productiva existente entre las UBPC y el sistema de innovación nacional, territorial y municipal,en términos de innovación - cooperación - aprendizaje, lo que les permitiría (a las UBPC) conocer e introducir los principales logros y resultados científicos obtenidos por nuestras instituciones de investigación y desarrollo (I+D) en diferentes escalas de producción.

Por el lado de la demanda, la propia expansión del turismo (como uno de los principales renglones económicos del país), ha incrementado las necesidades de mayores volúmenes de alimentos, ejerciendo al mismo tiempo mayor presión sobre los suministros disponibles para la población, generando la necesidad de aumentar las importaciones de alimentos.

Debemos destacar que sobre las bases político-ideológicas en que descansa el modelo económico de Cuba de igualdad social y garantías plenas de derechos para todos sus ciudadanos será extremamente difícil (pero no imposible) alcanzar el objetivo de la seguridad alimentaria planteado con la Tercera Reforma Agraria. O sea, por un lado, tenemos producción limitada de alimentos, grande escasez de divisas, recrudecimiento del bloqueo económico por parte de los EUA y del otro el aumento de los precios de los alimentos en el mercado internacional lo cual encarece cada vez más los volúmenes de importación, dificultando en última instancia el cumplimiento de alcanzar la soberanía alimentaria. 
Ante esta situación, resulta evidente y necesario que el gobierno resuelva de vez todas las dificultades negativas observadas desde la óptica de la oferta; es decir, los problemas negativos observados del lado de la producción agropecuaria y destrabé todos los obstáculos, entiéndase elimine o cree nuevas, normativas, resoluciones, leyes, formas de actuación directas, etc., que permitan y garanten el desarrollo pleno de las fuerzasproductivas del sector agropecuario.

El desafío es muy grande, toda vez que con las transformaciones realizadas dentro de la sociedad cubana, a partir de los años 90, es posible que en el futuro próximo surja una nueva clase social. Hoy existen aproximadamente 580 mil personas trabajando en el sector privado, quienes en Cuba se llaman trabajadores por cuenta propia, y cerca del $80 \%$ de esos trabajadores están ocupados en el sector de comercio y servicios.

Hoy existen 3,8 millones de trabajadores que dependen del Estado y coexisten aproximadamente 1 millón de trabajadores organizados en cooperativas estatales y mixtas. En términos socio económicos significa que tenemos un sector privado con renta superior que la de los trabajadores del sector estatal y que aún no están organizados como clase.Lo anteriormente planteado es de vital importancia porque a partir de 2018 la realidad socio política de Cuba tendrá como rasgo fundamental la continuidad del proceso de cambio generacional dentro de los mandos más importantes del gobierno. A partir de ese momento se abrirá una nueva etapa que tratarán de aprovechar los adversarios de la revolución, los cuales intentarán revertir las bases de la ésta.

Lo que hemos descrito seguirá siendo la batallaprincipal en la consolidación de la independencia cubana: mantener laopción socialista saludable, abierta, sostenible, no ya en eldiscurso, sino en la práctica permanente.

En síntesis, el análisis de la cuestión agraria y la tercera reforma agraria realizada en este periodo,refleja (aunque sin resultados económicos expresivos y grandes dificultades materiales) el predominio de las decisiones de Política sobre la Economía, lo que significa, ante todo,el predominio del interés colectivo sobre el individual, o lo que es lo mismo defender y salvar todas las conquistas sociales de la Revolución, siendo ese el granreto inmediato y futuro. 
Polis, Revista Latinoamericana, $N^{\circ} 47,2017$

\section{Notas}

${ }^{1}$ Entendida como la necesidad de la nación de mantener y desarrollar su propia capacidad de producir alimentos que son decisivos para la seguridad alimentaria nacional y comunitaria, respetando la diversidad cultural y la diversidad de los métodos de producción.

${ }^{2}$ Castro Ruiz, Fidel (1974). Discurso pronunciado por el comandante en jefe Fidel Castro Ruz en el acto celebrado por el aniversario de la muerte del líder campesino Niceto Pérez, el XV aniversario de la firma de la primera Ley de Reforma Agraria y el XIII aniversario de la ANAP, efectuado en La Plata, Sierra Maestra, el 17 de mayo de 1974. Disponible en: http://www.fidelcastro.cu/es/discursos/discurso-pronunciado-enel-acto-celebrado-por-el-aniversario-de-la-muerte-del-lider. Acceso: 20/05/017.

${ }^{3}$ Tesis y Resoluciones del I Congreso del PCC. Disponible en: http://congresopcc.cip.cu/ wp-content/uploads/2011/03/I-Congreso-PCC.-Tesis-y-Resoluciones-sobre-la-cuestión-agraria-y-las-relaciones-con-el-campesinado.pdf. Pag. 31.

${ }^{4}$ MP: millones de pesos.

${ }^{5}$ CASTRO. F: Discurso de conmemoración del 25 Aniversario de MININT, en Periódico Granma. 15 junio 1986, pág. 3. 


\section{Bibliografia}

CEPAL, (2017).CEPALSTAT. Base de datos y publicaciones estadísticas. Recuperado de: http://estadisticas.cepal.org/cepalstat/ WEB_CEPALSTAT/estadisticasIndicadores

CEPAL, (1984).Estudio acerca de la erradicación de la pobreza en Cuba.

CEPAL, (1979).Projeto CEPAL/UNCTAD/PNUD-RLA/76/013. Pino, O. yMartínez, O (Consultores). Relações económicas entre países de América Latina e os países do Conselho de Ajuda Mutua Econômica (COMECOM).

Figueroa, V. y Averhoff, A. (2001).La agricultura cubana y la reforma agraria de 1993. En: FAO, Boletín: Reforma agraria, colonización y cooperativas, Dirección del Desarrollo Rural. Roma: FAO. Recuperado de: http://www.fao.org/docrep/005/Y2519T/y2519t00.htm\#TopOfPage

Guevara, M. (2009).Cuba: reforma y transformación agraria. La crisis de los noventa y el proceso de desestatalización de la agricultura. Revista IDEAS, 3 (1) p .6- 29. Recuperado de: https://dialnet.unirioja.es/ descarga/articulo/4059613.pdf

Nova, A. (2008). El sector agropecuario en Cuba. Revista Nueva Sociedad. No 216. Disponible en: http://www.nuso.org. Acceso el 4/06/2017.

Nova, A.(s/d). La propiedad en la economía cubana Recientes cambios en las formas de propiedad y su impacto en el sector agrícola cubano. Recuperado de: http://espaciolaical.org/contens/publicacion/libro1/cap-4.pdf

Nova, A. (2001). Las cooperativas agropecuarias en Cuba: 1959-presente. En C, Harnecker, Cooperativas y socialismo: una mirada desde Cuba. La Habana, Cuba: Editorial Caminos.

FAO (2016). Statistic. DATABASE. FAOSTAT. 2016. Recuperado de: http:/ /www.fao.org/statistics/en/

Balado, B. y Trujillo, C. (2010). Los cambios estructurales en la agricultura cubana. La Habana, Cuba: Asociación Nacional de Economistas de Cuba (ANEC).

Valdés, J. (2009). Los Procesos de Organización Agraria en Cuba, 19592006.La Habana, Cuba: Fundación Antonio Núñez Jiménez.

$$
* * *
$$

Recibido: 08.06.17

Aceptado: 03.07.17 